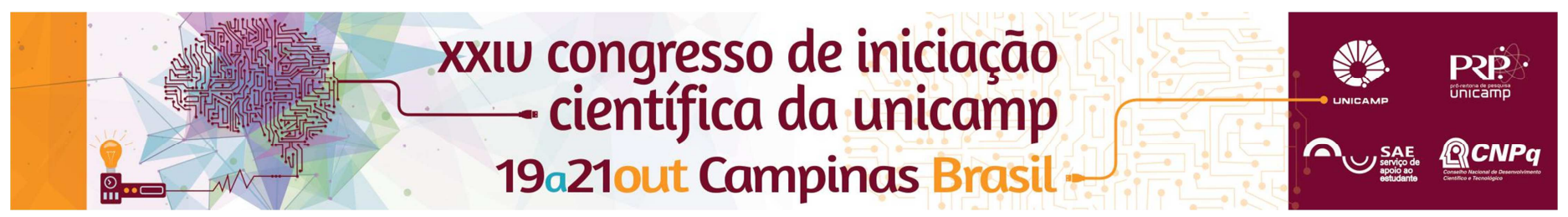

\title{
Robótica Pedagogica na Aprendizagem de Conceitos Cientificos
}

\author{
Matheus Dias de S. Galvão*, João Vilhete V. D'Abreu.
}

\begin{abstract}
Resumo
A Robotica Pedagógica é uma área de conhecimento que envolve o uso de recursos tecnológicos que englobam interação de diversos conceitos de Fisica, Matemática, Quimica, Engenharia, de diferentes campos de saber desde os mais simples até os mais complexos. A proposta deste trabalho é apresentar aos professores de Ensino Fundamental I e II, diversas possibilidades de utilização da Robotica Pedagógica para diversificar a forma de se trabalhar, de maneira interdisciplinar, o aprendizado de conceitos científicos. Para isso estão sendo desenvolvidos dispositivos robóticos cujos princípios de construção, automação e controle, na sala de aula, envolvem interação com conteúdos curriculares.
\end{abstract}

\section{Palavras-chave:}

robotica pedagogica, conceitos científicos, aprendizagem

\section{Introdução}

Para introduzir a ideia de robótica pedagógica iniciamos com a implementação/construção de dispositivos robóticos cujo funcionamento envolve alguns princípios mecânicos de máquinas que fazem parte do nosso cotidiano. Além disso, utilizamos interfaces eletrônicas mais didáticas, visto que estamos trabalhando com professores e alunos de ensino fundamental I e II. A automação e controle foi baseada no ArduBlock que que é um ambiente de programação em blocos. A construção do sistema mecânico, com peças Atto Box, LEGO, e materiais recicláveis, tem sido elaborada com vistas a estimular a criatividade $\mathrm{O}$ objetivo do projeto é propiciar aos professores autonomia no uso da robótica pedagógica, para que esta faça parte de seu método de ensino, e possa assim ser cada vez mais difundida no ramo educacional.

\section{Resultados e Discussão}

No ramo da tecnologia quanto maior o avanço e mais dinâmicas são suas aplicações, mais complexas são suas estruturas, na robótica pedagógica não é diferente. Temos diversas plataformas abertas que foram criadas para facilitar essas aplicações. Como um dos melhores exemplos temos o Arduino que otimiza de forma significativa a aplicação de conceitos científicos de automação e controle de componentes eletrônicos integrantes de robôs, que até então só poderiam ser discutidos por engenheiros e técnicos. Equipado com um hardware pronto apenas com entradas e saídas, e uma linguagem mundialmente difundida como " $\mathrm{C}$ " e adaptado para ambientes de programação em bloco como scratch e ardublok. o Arduino trouxe grandes avanços na robótica pedagógica, tornando sua aplicação cada vez mais difundida. Entretanto, tudo isso depende da formação de professores.
Figura 1. Dispositivos para aprendizagem de conceitos de Física, Matemática e alguns Princípios Mecânicos.

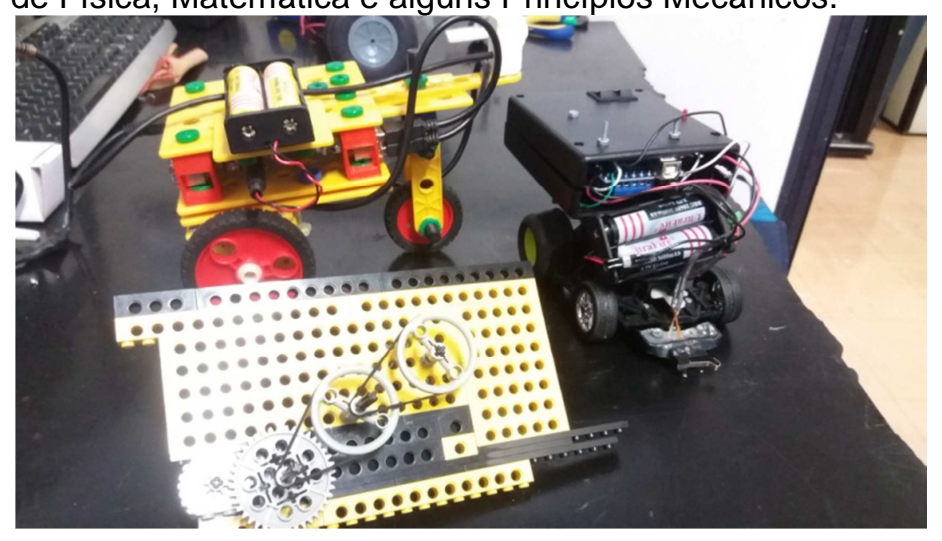

\section{Conclusões}

Apesar da dificuldade que de se inserir atividades extracurriculares atualmente no plano de aula dos professores, a tecnologia se faz cada vez mais presente em nossas vidas. Poder utilizá-la como ferramenta de ensino e aprendizagem só vem a trazer benefícios. Por mais demorada que seja a inserção da robótica na escola estamos certos de que este processo é irreversível. Tal como dizia Henri Ford, "O insucesso é apenas uma oportunidade para recomeçar de novo com mais inteligência".

\section{Agradecimentos}

Agradeço ao orientador João Vilhete V. D'Abreu pelo auxilio no aprendizado na área de "Robótica Pedagógica" Ao PRP/UNICAMP e o CNPq, pelo patrocínio incentivo à pesquisa e a direção da Escola Municipal de Educação Básica (EMEB) Vice Prefeito Antonio Mamoni pelas possibilidades de interação e aprendizagem que tem sido construída entre as partes envolvidas. 